\title{
Estimation of the Temperature in the Weld Penetration Channel in Electron Beam Welding
}

\author{
D. N. Trushnikov, E. S. Salomatova, V. Ya. Belenkiy
}

Perm National Research Polytechnic University, Perm, Russia.

Email: trdimitr@yandex.ru

Received September 2013

\begin{abstract}
In this paper, the method of experimental estimation of the temperature in a penetration channel in electron beam welding is described on the basis of chemical elements concentration in the vapors above welding zone. The temperature of a vapor-gas phase in the penetration channel is determined when equating calculated and experimental concentrations of the elements.
\end{abstract}

Keywords: Electron Beam Welding; The Chemical Composition of the Weld; Austenitny Stainless Steel; Thermodynamic Calculations; Steam Pressure in the Channel

\section{Introduction}

Electron beam welding (EBW) plays a special role among welding methods because of high power concentration in a welding electron beam and the ability of its deep penetration into the metal. These cause wide application of EBW in the manufacture of parts for critical products from various steels and alloys.

At the moment, there is a considerable success in the numerical simulation of electron beam and laser welding by static electron beam [2-4], but the complete dynamic models describing the processes in penetration channel at EBW with periodical influence on the electron beam are absent till present. The complicity and speed of these processes make it difficult to carry out computer simulation and numerical experiments even at the modern level, there is the necessity to search the ways for experimental investigations. Besides, when simulating laser welding, which is similar to the electron beam processes, the temperature in the penetration channel is usually taken to be equal to the boiling temperature at the atmospheric pressure, but electron beam welding is carried out under vacuum, and this approach for the simulation of electron beam welding is not suitable for getting the required accuracy of the results.

Experimental methods for measuring the temperature in the penetration channel also face with difficulties. The applying of pyrometrical methods is complicated by the significant value of secondary light emission from a welding zone.

\section{Research Methods}

In this paper the method of experimental estimation of the temperature in a penetration channel in electron beam welding is described on the basis of chemical elements concentration in the vapors above welding zone.

The background of the experimental technique was the determination of the temperature in a penetration channel in electron beam welding on the basis of chemical composition of the vapors formed above welding zone. For the experimental estimation of the vapor composition with the use of electron beam apparatus with the energy aggregate ELA-6VCh, produced by "SELMI" (Ukrane), oscillating electron beam passed along the sample made of austenitic steel 321. The plate made from aluminium alloy 512,0 (АМц-3) has been settled around the zone of electron beam influence on the sample (at a distance of $15 \mathrm{~mm}$ ). The material of the plate was chosen in terms of minimal coincidence of the alloy chemical composition with chemical composition of the steel 321. Electron beam power in the experiments was $3.6 \mathrm{~kW}$ (accelerating voltage was $60 \mathrm{kV}$ ), welding speed was $3.2 \mathrm{~mm} / \mathrm{s}$, oscillation frequency and amplitude of the beam were $650 \mathrm{~Hz}$ and $1 \mathrm{~mm}$, respectively.

The experiment pattern is shown in Figure 1. During the influence of oscillating electron beam on the sample, which was made from the steel 321, in dagger penetration mode, evaporation of the elements occurred with their following deposition on the plate made from aluminium alloy.

Later roentgen fluorescent analysis of the obtained 


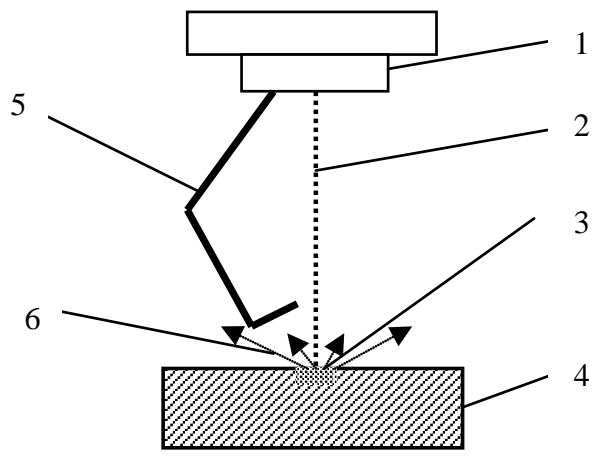

Figure 1. The experiment pattern on the analysis of the elements evaporation from steel 321 during electron beam action: 1-electron gun; 2-electron beam; 3-melt metal; 4-base material; 5-aluminium plate; 6-metal vapors from the zone of electron beam action.

coating, aluminium plate and the sample, which was influenced by electron beam, has been taken. Data obtained are represented in Tables 1-3.

The elements from the plate were subtracted from the chemical composition of the coating to determine the amount of alloying elements evaporated from the steel 321 during oscillating electron beam action. Results of the calculation are represented in Table 4.

Thus during electron beam influence on the sample, made from steel 321, an intensive evaporation of iron, chrome and manganese takes place.

Obtained experimental data were compared with the results of thermodynamic calculations to estimate the temperature in the penetration channel, which was formed in the metal by electron beam.

At thermodynamic calculations the content of each chemical element $C_{i}$ in vapor-gas phase of penetration channel was determined on the basis of the chemical composition of metal sample (Table 2) according to the equation:

$$
C_{i}=\frac{P_{i}}{P_{\text {total }}}
$$

where total vapor pressure $P_{\text {total }}$ in the channel is the sum of partial pressures of the elements from the alloy $\left(P_{i}\right)$.

It can be seen that vapor pressure in the channel mainly depends on the pressures of three elements which are iron, chrome and manganese.

Then the results of thermodynamic calculation, made with the use of the Equation (1), were compared with the results of chemical analysis of the deposited coating to estimate the temperature of a vapor-gas phase in penetration channel. Calculation results for the chemical composition of vapor-gas phase within the electron beam welding zone are represented in Figure 2 (only for iron, chrome and manganese, because the content of the other elements can be neglected), and the concentrations of chemical elements obtained with the use of roentgen flu-
Table 1. Chemical composition of aluminium plate (alloy 512,0 (АМц-3)).

\begin{tabular}{lllllllll}
\hline Chemical elements & $\mathrm{Al}$ & $\mathrm{Mn}$ & $\mathrm{Fe}$ & $\mathrm{S}$ & $\mathrm{Cro}$ & $\mathrm{Zn}$ & $\mathrm{Ti}$ & $\mathrm{Ni}$ \\
\hline
\end{tabular}

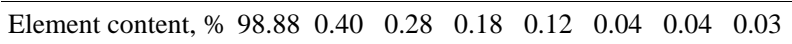

Table 2. Chemical composition of the sample (steel 321).

\begin{tabular}{cccccccc}
\hline Chemical elements & $\mathrm{Mn}$ & $\mathrm{Si}$ & $\mathrm{Cr}$ & $\mathrm{Ti}$ & $\mathrm{Ni}$ & $\mathrm{C}$ & $\mathrm{Fe}$ \\
\hline Element content, \% & 1.27 & 0.50 & 18.99 & 0.59 & 10.14 & 0.09 & 68.42
\end{tabular}

Table 3. Chemical composition of the coating.

\begin{tabular}{cccccc}
\hline Chemical elements & $\mathrm{Fe}$ & $\mathrm{Cr}$ & $\mathrm{Mn}$ & $\mathrm{Al}$ & $\mathrm{Ni}$ \\
\hline Element content, \% & 33.36 & 24.94 & 34.81 & 2.85 & 1.891 \\
\hline
\end{tabular}

Table 4. Amount of alloying elements evaporated from steel 321.

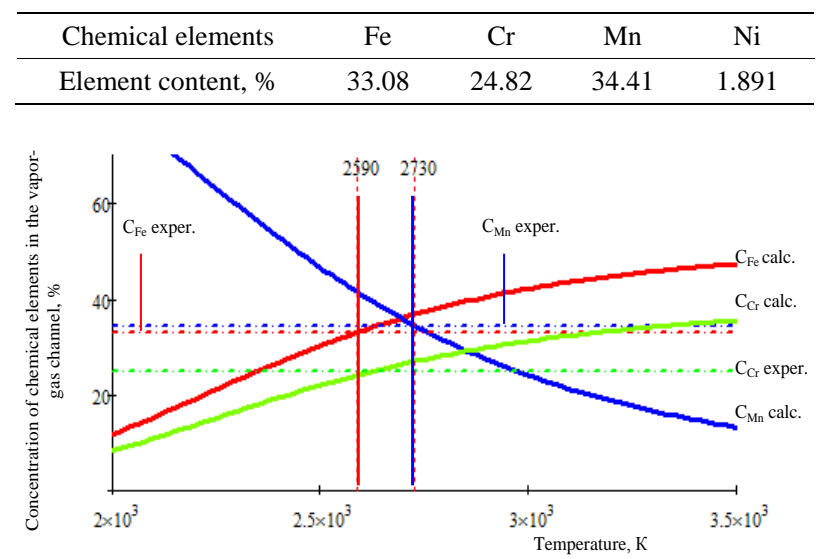

Figure 2. Correlation between iron, manganese and chrome concentrations in the channel for the steel 321 and the temperature.

orescent analysis at experimental research (horizontal lines) are also shown in the figure.

The temperature of a vapor-gas phase in the penetration channel is determined when equating calculated and experimental concentrations of the elements, and it was $2590 \mathrm{~K}$ (for Fe), $2610 \mathrm{~K}$ (for $\mathrm{Cr}$ ) and $2730 \mathrm{~K}$ (for Mn). As it is clear from the data obtained the difference between the temperatures is insignificant (about 5\%) and it can be caused by indirect character of the applied method which accuracy is still difficult to estimate.

Thus the temperature determined in the experiment on the basis of the analysis of components evaporation from steel 321 was $2600 \mathrm{~K}$. It is necessary to note that the temperature in the penetration channel is changeable in depth and undergoes fluctuations over time. When electron beam oscillating the zone of maximal energy release reciprocates from the surface to the depth of the channel and reverses [5], the temperature of any single element of the penetration channel becomes a periodic function. The time-average temperature rises with the depth increasing 
in the penetration channel. At the same time significant part of the vapors condenses on the walls during the movement from the depth of the penetration channel [6]. The statement concerned is confirmed with the analysis of the chemical composition of the weld seam along its depth, which shows that noticeable depletion of the metal with alloying elements takes place only in higher areas of metal. According to this, the described method allows to determine only a certain temperature of a higher part of penetration channel which corresponds to a time-average vapor composition. Obtained data are in a satisfactory agreement with the results of the work [4].

The research was carryed out under the support of the grants RFBR-Ural No. 11-08-96016, RFBR No. 13-0800397A and the financial support of the Ministry of education of the Perm region.

\section{Conclusions}

The method of experimental estimation of the temperature in the range of interaction of the beam and walls of penetration channel has been suggested. The method is based on vapor concentration measurement above welding zone with the use of chemical analysis of a film deposited on a substrate located near welding zone. The temperature of higher areas of the penetration channel, corresponding the time-average vapor composition at the welding with depth of $7 \mathrm{~mm}$ of the steel 321, was about $2600 \mathrm{~K}$. Experimentally determined temperature in the channel was in a good agreement with existing estimation.

The obtained results can be used further in the calcula- tion of intensity of evaporation processes in the channel it electron beam welding; this will permit to determine the corresponding costs of thermal energy and to take into account this factor at a numerical solution of the connected thermal and hydrodynamic problem.

\section{REFERENCES}

[1] A. F. H. Kaplan, P. Norman and I. Eriksson, “Analysis of the Keyhole and Weld Pool Dynamics by Imaging Evaluation and Photodiode Monitoring," Proceedings of LAMP 2009-The 5th International Congress on Laser Advanced Materials Processing, 2009, pp. 1-6.

[2] W.-I. Cho, S.-J. Na, C. Thomy and F. Vollertsen, "Numerical Simulation of Molten Pool Dynamics in High Power Disk Laser Welding," Journal of Materials Processing Technology, Vol. 212 , 2012, pp. 262-275. http://dx.doi.org/10.1016/j.jmatprotec.2011.09.011

[3] W. Sudnik, W. Erofeew, D. Radaj and S. Breitschwerdt, "Numerical Simulation of Weld Pool Geometry in Laser Beam Welding," Journal of Physics D: Applied Physics, Vol. 33, No. 6, 2000, pp. 662-671.

[4] R. Ray, T. A. Palmer, J. W. Elmer and T. Debroy, "Heat Transfer and Fluid Flow during Electron Beam Welding of 304 L Stainless Steel Alloy,” Welding Journal, 2009, Vol. 88, pp. 54-61.

[5] D. Trushnikov, V. Belenkiy, V. Shchavlev, A. Piskunov, A. Abdullin and G. Mladenov, "Plasma Charge Current for Controlling and Monitoring Electron Beam Welding with Beam Oscillation,” Sensors, 2012, pp. 17433-17445.

[6] H. Schwarz, "Mechanism of High-Power-Density Electron Beam Penetration in Metal," Journal of Applied Physics, Vol. 35, No. 7, 1964, pp. 2020-2029. http://dx.doi.org/10.1063/1.1702787 